\title{
Simulasi Jalur Evakuasi dan Pelatihan Identifikasi Kerusakan Bangunan Akibat Gempa dan Kebakaran di SMAK Cakranegara Mataram
}

\author{
Suryawan Murtiadi, Mudji Wahyudi, Didi S. Agustawijaya, I Wayan Yasa, Akmaluddin \\ Magister Teknik Sipil, Fakultas Teknik, Universitas Mataram, Indonesia.
}

Alamat korespondensi : s.murtiadi@unram.ac.id

\begin{abstract}
ABSTRAK
Lombok merupakan salah satu pulau yang memiliki tingkat kegempaan relatif tinggi. Gempa sering terjadi berupa gempa besar maupun gempa kecil yang tidak terekam. Permasalahan muncul akibat keterbatasan pengetahuan terhadap mitigasi bencana, khususnya para guru, siswa dan staf pada sekolahan. Infrastruktur terdampak gempa perlu segera dievaluasi untuk mengetahui tingkat kerusakannya agar dapat segera diperbaiki. Selain gempa, bahaya kebakaran merupakan ancaman yang berakibat fatal. Kebakaran didefinisikan sebagai berkobarnya api yang tidak terkendali. Program ini bertujuan untuk meningkatkan pengetahuan dan keterampilan masyarakat menghadapi bencana gempa dan risiko bahaya kebakaran. Metode pelatihan dilaksanakan dengan teknik presentasi disertai praktek identifikasi tingkat kerusakan dan metode perbaikan infrastruktur khususnya bangunan gedung dan rumah tinggal. Cara-cara perbaikan kerusakan dengan kriteria ringan sampai sedang diberikan dalam pelatihan ini. Pengetahuan tentang teknologi rumah tahan gempa juga diperkenalkan dalam forum penyuluhan. Pelatihan dan pembuatan ramburambu jalur evakuasi dipraktekkan dengan simulasi untuk keselamatan seluruh penghuni saat terjadi bencana gempa dan kebakaran. Simulasi dan evaluasi jalur evakuasi dimulai dari dalam bangunan gedung menuju tempat aman berupa titik kumpul (assembly point). Hasil yang diperoleh adalah peningkatan pengetahuan terhadap mitigasi bencana termasuk karakteristik gempa, kerusakan bangunan yang ditimbulkan, dan tatacara penyelamatan diri. Pemahaman pengetahuan tentang perbaikan kerusakan infrastruktur akibat gempa juga meningkat, terutama pada bangunan rumah tinggal sederhana. Pemahaman ini berfokus pada pentingnya ikatan antar komponen struktur bangunan mulai dari fondasi, sloof, kolom, dinding sampai pada konstruksi atap bangunan. Dari program Pengabdian Kepada Masyarakat ini diharapkan ke depan masyarakat akan lebih siap beradaptasi dan lebih tangguh menghadapi bencana, khususnya bencana gempa dan bahaya kebakaran.
\end{abstract}

Keywords: Gempa, kebakaran, pelatihan, identifikasi, bangunan

\section{PENDAHULUAN}

SMAK Kesuma Mataram berada di Pulau Lombok yang merupakan salah satu wilayah di Indonesia yang memiliki tingkat kegempaan relatif tinggi. Puja (2005) menyampaikan gempa sering terjadi di Pulau Lombok baik yang terekam maupun yang tidak terasa dan tidak terekam. Secara tektonik, Pulau Lombok yang terletak di NTB berada pada wilayah Busur Sunda bagian timur, membentang dari Selat Sunda ke timur hingga Pulau Sumba. Tingginya aktifitas seismik wilayah Pulau Lombok disebabkan karena kawasan ini diapit oleh dua sumber gempa, yaitu mega-thrust di Selatan dan back arc thrust di Utara pulau. Megathrust terbentuk sebagai sesar naik besar akibat tumbukan lempeng Indo-Australia dengan lempeng Erasia; sedangkan di utara Pulau Lombok terbentuk sesar naik di busur belakang.

Dampak dari gempa tektonik tersebut adalah kerusakan infrastruktur dan korban jiwa. Dampak kegempaan diukur dengan menggunakan skala Modified Mercalli Intensity (MMI), dengan nilai 1 hingga 12. Lebih lanjut, secara praktis risiko kegempaan bisa ditentukan menggunakan jarak 
gempa atau kedalaman gempa. Semakin dekat dengan sumber gempa, potensi bahaya gempa akan semakin besar (Guntoro, 2004).

Purwono, dkk. (2005) menyampaikan permasalahan gempa bumi dalam bidang konstruksi sangat menekankan pembangunan yang tahan akan beban gempa tersebut. SNI (2002) merujuk pada suatu filosofi konstruksi bangunan tahan gempa yakni apabila gempa kecil bangunan tidak mengalami kerusakan apapun, dan jika gempa sedang komponen non struktur boleh mengalami kerusakan, tetapi komponen strukturnya tidak boleh mengalami kerusakan dan apabila gempa kuat, komponen non struktur maupun komponen strukturnya boleh mengalami kerusakan namun masih sempat memberi kesempatan pada penghuninya untuk menyelamatkan diri.

Untuk infrastruktur, dampak bencana gempa tidak memandang fasilitas umum maupun fasilitas milik pribadi (Agustawijaya, 2018). Pada jenis bangunan tertentu misal rumah sakit, kampus, bandara, atau rumah hunian, yang akan menentukan kemampuan bangunan untuk tahan terhadap gempa atau tidak adalah ketahanan strukturnya. Maka, para praktisi konstruksi teknik sipil harus memahami kondisi kegempaan dimana bangunan tersebut akan dibangun, dan jenis bangunan apa yang akan dibangun. Biasanya praktisi muda belum mempunyai pengalaman dan pengetahuan yang memadai akan rekayasa kegempaan dalam pekerjaannya di bidang teknik sipil. Asrurifak, dkk. (2010) menyatakan diperlukannya induksi untuk mempercepat pemahaman tentang rekayasa gempa dalam bidang teknik sipil.

Infrastruktur yang telah mengalami kerusakan pasca gempa perlu segera dievaluasi untuk mengetahui penyebab kerusakan, elemen-elemen struktur yang mengalami kegagalan dan metode perbaikan atau perkuatan struktur. Metode perkuatan struktur seperti penyelubungan (jacketing) dengan bahan baja, baja spiral, beton atau komposit. Penambahan tulangan luar dilakukan dengan bahan steel strap/plate dan tulangan sengkang, Penulangan luar berupa pelat baja, injeksi epoksi, dan metode perkuatan dengan menggunakan Fiber Reinforced Polymer.

Pawirodikromo (2012) menyatakan koefisien gempa sangat dipengaruhi oleh kondisi geologi setempat. Rambatan gempa bergetar secara horizontal pada batuan keras pada jarak yang jauh dari pusat gempa, kemudian merambat secara vertikal ke tanah lunak yang ada di atasnya untuk disampaikan ke permukaan. Rambatan ini dipengaruhi oleh ketebalan batuan dan struktur geologinya.

Kerusakan yang ditimbulkan oleh adanya gempa, misalnya pada bangunan, diantaranya terjadi kerusakan pada sambungan dan retakan pada dinding. Besarnya kerusakan ini tergantung pada percepatan rambatan, lamanya pergerakan, frekuensi pergerakan dan karakteristik struktur (Daniel dan Ada, 1995). Penyebab kerusakan ini adalah momen inersia oleh pergetaran permukaan, tenaga induksi dari gempa, perubahan sifat fisik tanah pondasi, pergeseran langsung dari sesar yang terjadi, longsor, tsunami, dan perubahan elevasi akibat tektonik. Kerusakan paling parah yang menyebabkan banyak korban adalah kerusakan akibat pergetaran pemukaan (Natawijaya, 2005). 


\section{METODE KEGIATAN}

\section{Lokasi Pelaksanaan Kegiatan}

Lokasi pelaksanaan pelatihan identifikasi kerusakan infrastruktur dilaksanakan di SMAK Kesuma Cakranegara, Mataram. Pelaksanaan kegiatan dilakukan di dalam Gedung Sekolah mencakup ruang kelas, ruang kantor, koridor, dan tangga antar tingkat bangunan.

Dalam melaksanakan pelatihan identifikasi ini, dan untuk mendapatkan hasil yang sesuai dengan target yang diinginkan, penetapan metode pelaksanaan menjadi sangat penting sehingga pelaksanaan kegiatan menjadi mudah dan tepat sasaran. Kegiatan yang dilakukan diantaranya yaitu:

1. Pengenalan kegempaan di Pulau Lombok

2. Pengenalan tingkat-tingkat kerusakan infrastruktur akibat gempa

3. Tata cara perbaikan kerusakan infrastruktur

4. Pengenalan bangunan tahan gempa

5. Tinjauan dan identifikasi kerusakan infrastruktur akibat gempa

6. Metode perbaikan infrastruktur akibat gempa

7. Memahami konsep dasar api dan jenis kebakaran

8. Memahami manajemen keselamatan kebakaran gedung.

\section{Gambaran Iptek yang Diperkenalkan}

Gempa menyebabkan terjadinya kerusakan infrastruktur baik rumah tinggal, bangunan pemerintah, fasilitas umum, jalan, jembatan dan bangunan keairan. Kriteria tingkat kerusakan infrastruktur diantaranya rusak ringan, sedang dan berat. Kemampuan masyarakat dalam melakukan identifikasi kerusakan infrastruktur rata-rata sangat rendah, sehingga dalam upaya melakukan perbaikan terbatas.

Dalam upaya meningkatkan pemahaman masyarakat terhadap kerusakan bangunan infrastruktur pada kegiatan ini dilakukan transfer pengetahuan dan teknologi. Sangat perlu disampaikan kepada masyarakat mengenai tingkat-tingkat kerusakan infrastruktur dan upaya perbaikan bangunan dengan tingkat kerusakan ringan dan sedang. Gambaran iptek yang diperkenalkan adalah:

1. Pengenalan tingkat kerusakan bangunan

2. Metode identifikasi kerusakan bangunan

3. Langkah perbaikan kerusakan bangunan

Boen (2016) melakukan identifikasi tingkat kerusakan bangunan dan tindakan yang harus dilakukan masyarakat yang disajikan pada Gambar 1 dan 2. 


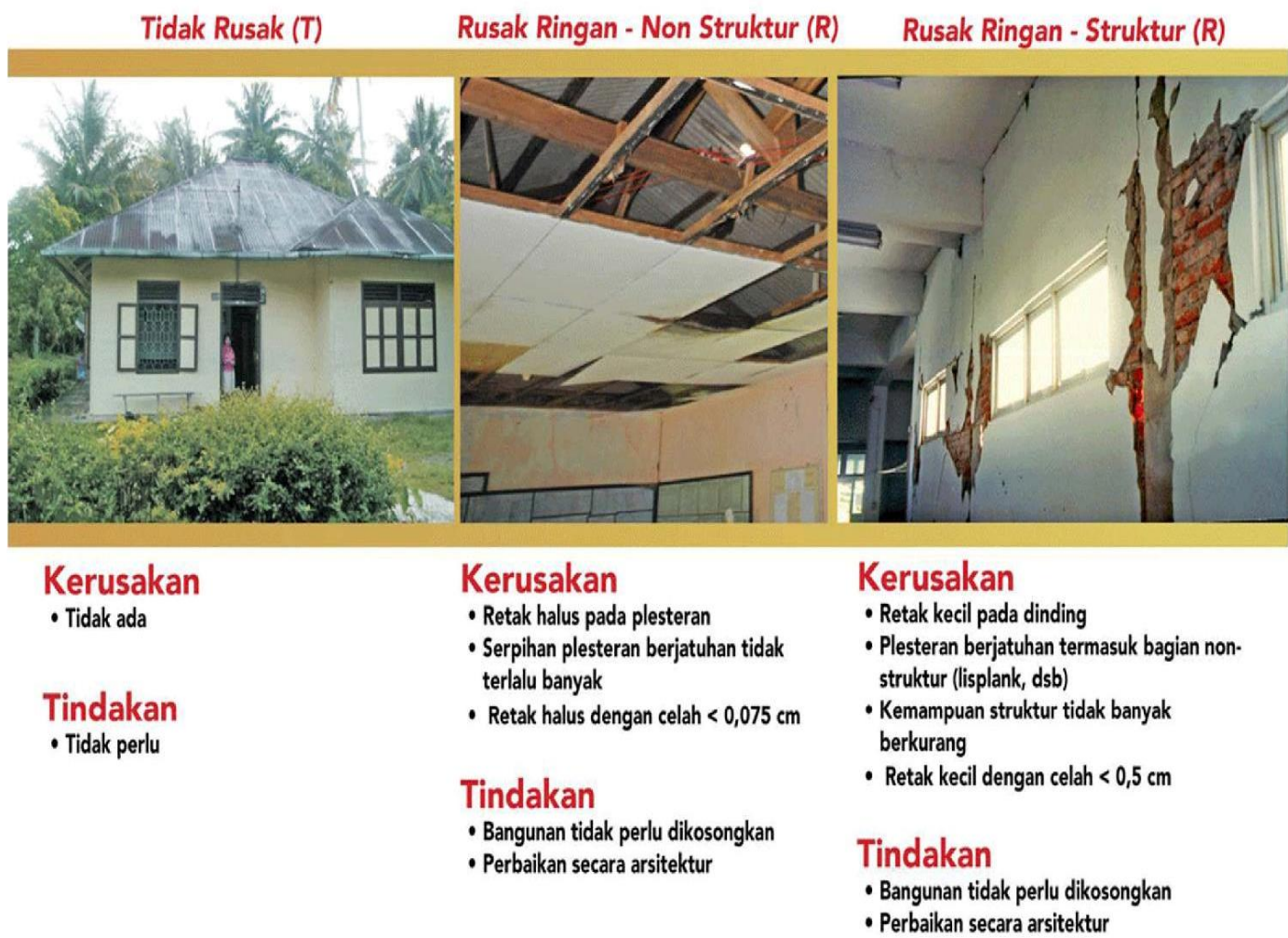

Gambar 1 Bangunan Tidak Rusak Sampai Rusak Ringan dan Tindakan yang Dilakukan

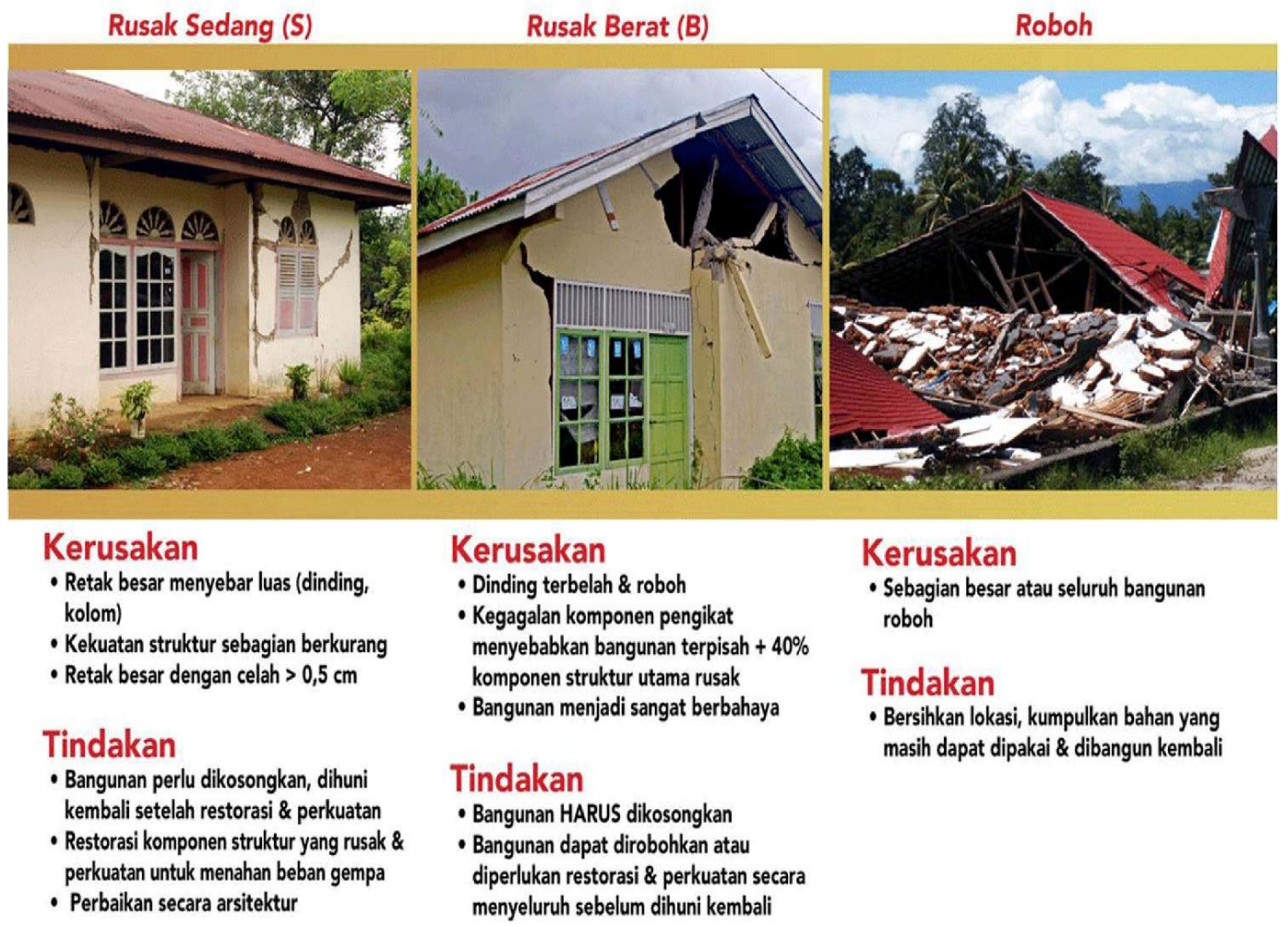

Gambar 2 Bangunan Rusak Sedang Sampai Roboh Akibat Gempa dan Tindakan yang Dilakukan 


\section{HASIL DAN PEMBAHASAN}

\section{Hasil Kegiatan}

Berdasarkan catatan dari hasil diskusi dan tanya jawab pada kegiatan ini, beberapa hal penting yang diperlukan untuk pemahaman masyarakat terkait perbaikan infrastruktur dapat disarikan sebagai berikut:

1. Kualitas suatu bangunan secara internal sangat dipengaruhi oleh tiga faktor yaitu: ketrampilan tukang, mutu bahan dan kelengkapan peralatan. Ketiga faktor ini harus diperhatikan karena saling berkaitan. Pengabaian salah satu faktor saja akan mengakibatkan turunnya kekokohan bangunan secara signifikan.

2. Penambahan perkuatan pada elemen struktur tahan gempa akan menambah biaya sekitar $15 \%$ dari biaya pembangunan biasa.

Dari hasil diskusi juga diperoleh saran dari beberapa tokoh masyarakat yang sangat tertarik dengan kegiatan ini. Saran mereka adalah agar kegiatan penyuluhan dan pelatihan seperti ini lebih sering dilakukan karena bermanfaat bagi warga yang terdampak gempa.

\section{Jalur Evakuasi}

Jalur evakuasi adalah jalur yang dipakai manusia untuk menyelamatkan diri saat terjadi bencana atau suatu kejadian yang tidak diinginkan. Oleh sebab itu keberadaan jalur dan sarana evakuasi merupakan salah satu hal yang diutamakan. Pentingnya melakukan evaluasi pada jalur dan sarana evakuasi adalah salah satu cara dalam mengurangi jatuhnya korban pada saat terjadi bencana. Jalur evakuasi yang ideal adalah jalur yang terpendek, tercepat dan teraman menuju tempat yang dianggap aman untuk menghindari keadaan darurat tersebut. Evaluasi pada jalur dan sarana evakuasi sangat perlu dilakukan secara berkala.

Penerapan Sistem Manajemen Keselamatan dan Kesehatan Kerja mengatur para pengusaha konstruksi wajib melakukan pemantauan dan evaluasi kinerja K3. Evaluasi dapat diartikan sebagai suatu proses sistematis dalam memeriksa, menentukan, membuat keputusan atau menyediakan informasi terhadap program yang telah dilakukan dan sejauh mana program tersebut tercapai. Jalur evakuasi merupakan akses yang dapat dinyatakan aman untuk dilalui sebagai jalur menuju sarana evakuasi atau ke tempat yang aman untuk menghindari bahaya. Sarana evakuasi dapat diartikan sebagai suatu tempat yang dijadikan titik kumpul paling aman untuk sementara untuk menyelamatkan diri.

Proses mengevaluasi jalur dan sarana evakuasi dapat dilakukan dengan beberapa cara. Jalur dan sarana evakuasi harus direncanakan dengan baik sejak perancangan bangunan sesuai rencana penggunaannya. Pertama, dalam evaluasi perlu adanya analisis sirkulasi, yaitu pola penataan ruang dalam yang terjadi pada bangunan ini akan mempengaruhi aksesibilitas evakuasi penghuni dalam kondisi darurat, sehingga hal tersebut sangat penting untuk diperhatikan. Kedua, analisis sarana jalur evakuasi menurut SNI 03-1746-2002 bahwa Sarana dan Prasarana Jalur Evakuasi meliputi pengeras suara, tangga evakuasi, pintu evakuasi, signage (rambu), dan assembly point (titik kumpul). Jalur evakuasi pada anak tangga dan koridor harus merupakan jalur yang bersih dan bebas hambatan seperti yang ditunjukkan dalam Gambar 3. 


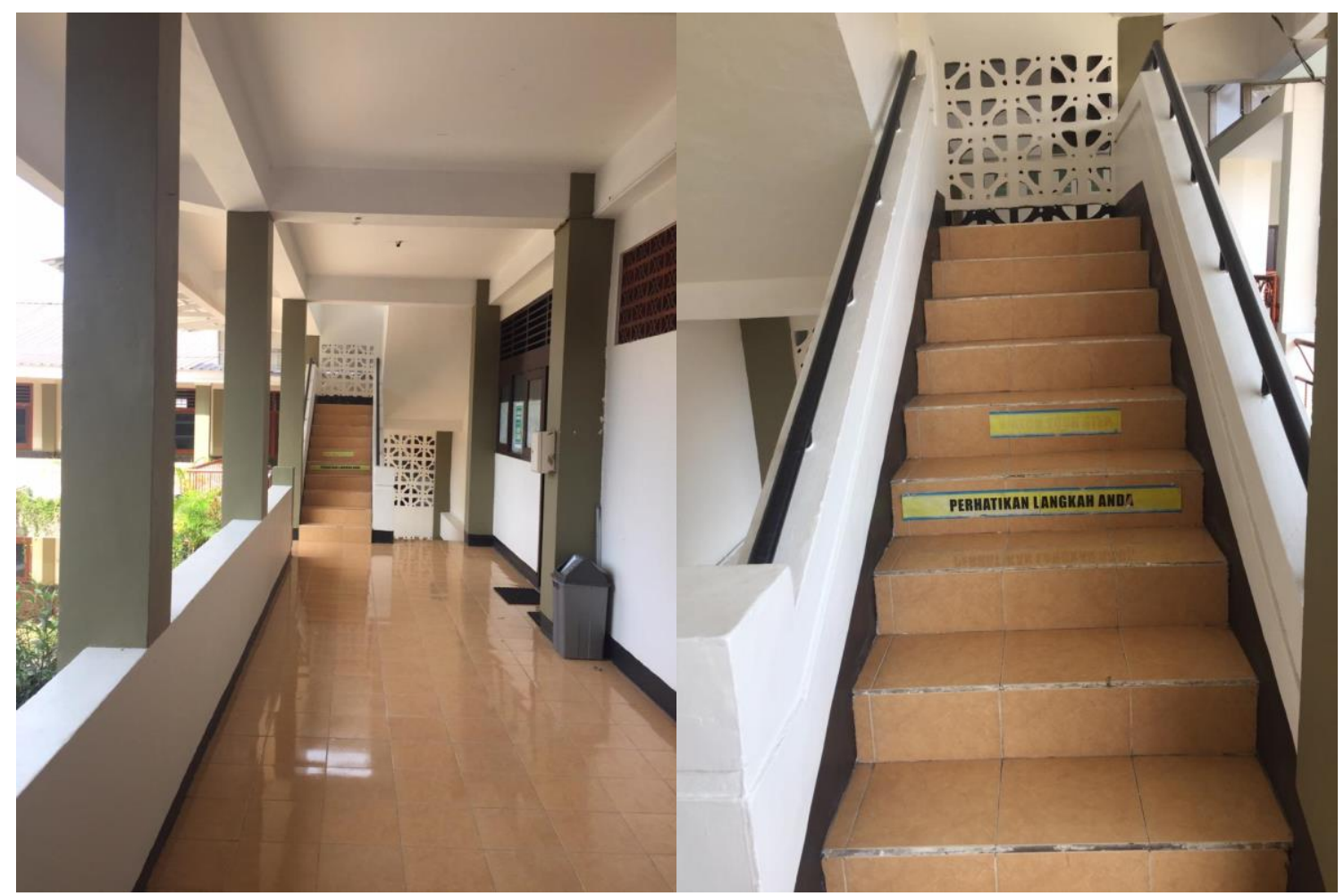

Gambar 3 Anak Tangga dan Koridor Bebas Hambatan untuk Jalur Evakuasi

\section{Rambu Evakuasi}

Penempatan rambu jalur evakuasi perlu diperhatikan karena tidak jarang rambu evakuasi tidak perhatikan atau dianggap kurang penting. Kenyataannya, rambu sangat membantu dalam mengarahkan ke tempat evakuasi. Menurut Peraturan Menteri Pekerjaan Umum No.26/PRT/M/2008, pada saat proses evakuasi, penghuni bangunan harus memiliki waktu yang cukup untuk menyelamatkan diri dengan aman dan meninggalkan gedung. Direktorat SDMO ITS (2019) memberi beberapa contoh rambu jalur evakuasi saat terjadinya bencana yang disajikan pada Gambar 4 (a), (b), dan (c).
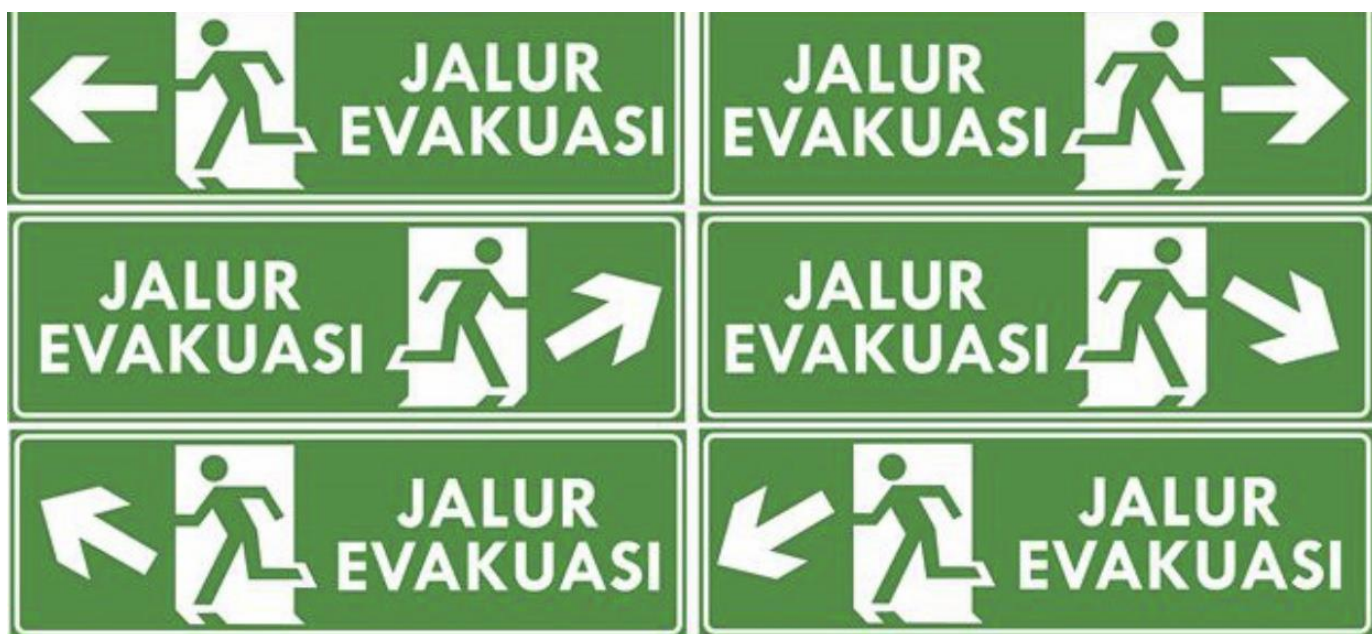

(a) Rambu petunjuk arah jalur evakuasi 


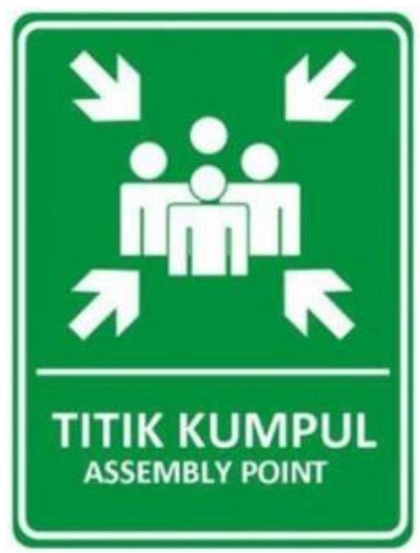

(b) Rambu jalur evakuasi pada tangga

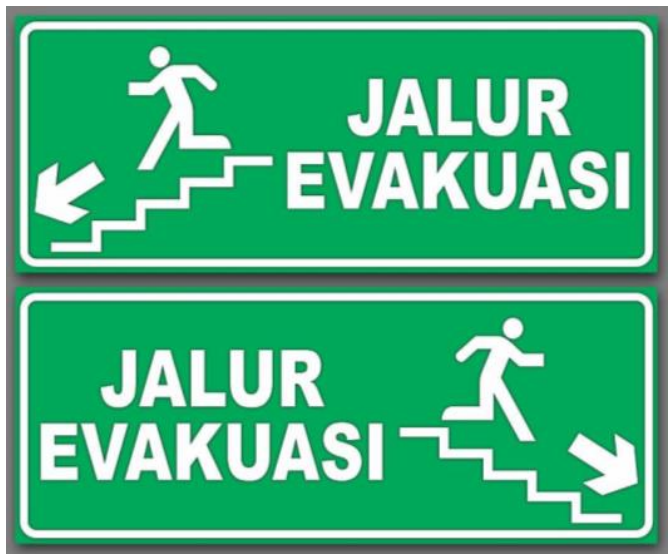

(c) Rambu tempat titik kumpul

Gambar 4 (a) (b) (c) Jenis-jenis rambu jalur evakuasi

Keterangan gambar:

- Warna dasar putih dari bahan yang lentur dan tidak mudah sobek.

- Warna hijau reflective memantulkan cahaya.

\section{KESIMPULAN DAN SARAN}

Kesimpulan dari pelaksanaan program Pengabdian Kepada Masyarakat di SMAK Kesuma Mataram ini dapat ditarik kesimpulan yakni pelaksanaan kegiatan, baik penyuluhan maupun pelatihan identifikasi tingkat kerusakan dan upaya perbaikan infrastruktur pasca gempa di SMAK Kesuma Cakranegara Mataram, berjalan dengan lancar sesuai harapan, dan terjadi dialog interaktif antara peserta dan pelaksana penyuluhan dan pelatihan. Peserta sangat bersemangat untuk segera mempraktekkan cara perbaikan bangunan pasca gempa, dan realisasi perbaikan infrastruktur pasca gempa mampu memberikan manfaat kepada para guru, murid, dan staf diharapkan pengetahuan ini dapat ditularkan pada masyarakat di lokasi lain yang terdampak gempa dan kebakaran.

Saran yang dapat disampaikan setelah berhasilnya pelaksanaan pengabdian ini yakni disarankan memberikan penjelasan secara holistic dan komprehensif disertai contoh-contohnya selama kegiatan. Hal ini disebabkan pada saat tanya jawab diketahui bahwa masyarakat masih awam terhadap informasi menyeluruh dalam mengantisipasi hal-hal yang berhubungan dengan perbaikan infrastruktur pasca gempa dan kebakaran, dan kegiatan serupa ini disarankan lebih sering dilakukan karena sangat bermanfaat bagi warga terutama di kawasan permukiman yang berpotensi terdampak gempa dan bahaya kebakaran.

\section{UCAPAN TERIMA KASIH}

Penulis mengucapkan terima kasih kepada Lembaga Penelitian dan Pengabdian Kepada Masyarakat (LPPM) Universitas Mataram atas dukungan finansial terhadap kegiatan Pengabdian Kepada Masyarakat ini.

\section{DAFTAR PUSTAKA}

Agustawijaya, D.S., 2018. Geologi Teknik, Penerbit Andi, Yogyakarta. 
Asrurifak, M., Irsyam, M., Budiono, B., Triyoso, W., Hendriyawan, 2010. Development of Spectral Hazard Map for Indonesia with a Return Period of 2500 Years using Probabilistic Method, Civil Engineering Dimension, Vol. 12, No. 1, March 2010, 52-62.

Boen, T., 2016. Belajar dari Kerusakan Akibat Gempa Bumi: Bangunan Tembokan Nir-Rekayasa di Indonesia, Gadjah Mada University Press, Yogyakarta.

Daniel, F., Ada, L., 1995. Earthquake Engineering and Earthquake-Resistant Design, Department of Civil Engineering, Illinois Institute of Technology, USA.

Direktorat SDMO ITS, 2019. Standard Safety Sign (Tanda Keamanan Standar), Direktorat Sumber Daya Manusia dan Organisasi, Institut Teknologi Sepuluh Nopember, Surabaya.

Guntoro, A., 2004. The relationship between tectonic development of Central Indonesian region and collision of Banggai Sula microcontinent to the East Sulawesi, Jurnal Teknologi Mineral (JTM), Vol. XI No. 1/2004, pp. 3-14.

Pawirodikromo, W., 2012. Seismologi Teknik \& Rekayasa Kegempaan, Pustaka Pelajar, Yogyakarta.

Puja, I.P., 2005. Informasi monitoring gempabumi dan tsunami, Seminar Nasional Gempabumi dan Tsunami (Potensi dan Mitigasi), IAGI, Mataram, 19 Februari 2005.

Purwono, R., Subakti, A., Wimbadi, I., Irmawan, M., 2005. Perencanaan Struktur Beton Bertulang Tahan Gempa, ITS Press, Surabaya.

SNI, 2002. Standar Nasional Indonesia SNI 03-1726-2002, Tata Cara Perencanaan Ketahanan Gempa untuk Bangunan Gedung, Badan Standardisasi Nasional (BSN), Jakarta. 